\title{
MODEL MODERASI BERAGAMA BERBASIS PESANTREN SALAF
}

\author{
Ali Nurdin \\ Universitas Islam Negeri Sunan Ampel Surabaya \\ Email: ali.nurdin@uinsby.ac.id \\ Maulidatus Syahrotin Naqqiyah \\ Universitas Islam Negeri Sunan Ampel Surabaya \\ Email: maulinaqqy@gmail.com
}

\begin{abstract}
Pondok Pesantren Salaf Al-Anwar, Sarang, Rembang, Central Java, is one of pondok pensantrens based on Nahdlatul Ulama's moderat (tawassut) understanding, and adheres to the teachings of abl al-sunnab wa al-jama'ah. The purpose of this study is to understand and describe the religious moderation model developed and implemented at Al-Anwar. The results of this descriptivequalitative study show that the religious moderation model carried out at Al-Anwar is a model of implementing an educational system based on the Salaf curriculum, in which message materials are based on the books of turäth. This model, along with kiai's strong creibility, become an effective media in instilling moderate attitudes for 'santri' and the society. The implementation of religious moderation in pesantren can be done through the attitudes and behaviors of santri, which are always guided by the pesantren's two principles of thought: Firstly, 'santri' must have special knowledge as a provision for themselves and general knowledge to face their community. Secondly, 'santri' in solving social problems must always refer to the four pillars of the nation.
\end{abstract}

Keywords: Religious moderation; salaf pesantren; two principles of thought.

\section{Pendahuluan}

Agama Islam hadir sebagai jalan tengah (tawassut) dengan pelbagai konsep yang meneduhkan dalam bidang akidah, ibadah, akhlak, hubungan antarsesama umat manusia, dan perundang- 
undangan. ${ }^{1}$ Meskipun demikian, ekstremisme dalam beragama merupakan sebuah fenomena yang sering terjadi dalam lintasan sejarah kehidupan umat Islam. Dalil-dalil dalam Islam selalu menunjukkan seruan pada sikap i iitidāl (sikap tengah-tengah, moderasi), dan melarang sikap berlebih-lebihan yang dikenal dengan dengan ghuluw (kelewat batas), fanatik, sok pintar, tashdid (mempersulit). ${ }^{2}$ Dalam al-Qur'ān, kata'adl yang berarti "tengah" juga disebutkan dengan perkataan lain, yaitu al-wast dan al-qișt yang kesemuanya memiliki makna "tengah" atau mengambil sikap tengah. Demikian pula terdapat kata al-wazn atau al-mizañ yang bermakna keseimbangan atau sikap yang berimbang. ${ }^{3}$ Ibn Taymìnah mengatakan bahwa dengan keadilan dan keseimbangan, peradaban yang kukuh akan terwujud, sebab keadilan merupakan landasan moral yang sangat kuat bagi pembangunan peradaban manusia di sepanjang sejarah, dan sebaliknya, tanpa adanya keadilan maka akan muncul ancaman terhadap kelangsungan hidup umat manusia. ${ }^{4}$

Pesantren salaf memiliki tradisi transformasi keilmuan agama yang spesifik dan terpusat pada model ngaji sebagai bentuk pembelajaran kepada para santri dengan menggunakan kitab-kitab kuning (kitab turäth) yang biasanya di lakukan setiap selesai jamaah salat wajib. ${ }^{5}$ Sistem pembelajaran pesantren berbasis kitab-kitab klasik diajarkan tanpa kesudahan dengan penjelasan sesuai konteks yang terjadi dalam masyarakat, termasuk moderasi dalam beragama. ${ }^{6}$ Sistem pendidikan pesantren masih diperlukan untuk

1 Iffati Zamimah, "Moderatisme Islam dalam Konteks Keindonesiaan (Studi Penafsiran Islam Moderat M. Quraish Shihab)", Al-Fanar: Jurnal Ilmu Al-Qur'an dan Tafsir, Vol. 1, No. 1 (2018), 76.

2 Yusuf Qardhawi, Islam Ekstrem: Analisis dan Pemecabannya (Bandung: MIZAN, 1993), 17.

3 Nurcholis Madjid, Islam Kemodernan dan Keindonesiaan (Bandung: MIZAN, 1993), 57.

${ }^{4}$ Ibn Taymìyah, Al-Amr bi al-Ma'rūf wa al-Naby 'an al-Munkar, ed. Șalāh al-Dīn alMunajjad (Beirut: Dār al-Kitāb al-Jadīd, 1396), 40.

5 Ali Anwar, Pembaruan Pendidikan di Pesantren Lirboyo Kediri (Kediri: IAIT Press, 2008), 1.

6 Abdurrahman Wahid, Menggerakkan Tradisi: Esai-Esai Pesantren (Yogyakarta: LKiS, 2001), 4. 
menanamkan nilai-nilai Islam secara moderat dengan kegiatan pengajian mingguan, istighäthah, dan sebagainya ${ }^{7}$.

Penelitian ini dilakukan berdasarkan asumsi bahwa moderasi beragama berbasis pesantren dipahami sebagai suatu upaya yang dilakukan oleh pesantren dalam menanamkan nilai-nilai Islam moderat pada santri dan masyarakat, yaitu pemahaman yang memiliki keseimbangan nalar dan berpikir realistik, serta merujuk pada berbagai sumber yang komprehensif dan konsisten ${ }^{8}$ moderasi dalam beragama di pesantren ditanamkan melalui lembaga pendidikan formal dan non-formal; ${ }^{9}$ pesantren mengembangkan nilai-nilai multikultural yang adaptif dengan model pendidikan tanpa dikotomik; ${ }^{10}$ pesantren mengembangkan ajaran Islam yang moderat di Indonesia, ${ }^{11}$ yang memiliki karakter toleran yang tinggi, menghormati tradisi lama yang masih relevan, progresif, dan membebaskan. ${ }^{12}$ Pesantren melahirkan karakter Muslim yang memiliki basis moderat dalam menghadapi dinamika kehidupan yang terus berubah. ${ }^{13}$

Penelitian ini bertujuan untuk memahami dan mendeskripsikan model moderasi beragama yang dikembangkan dan diimplementasikan Pondok Pesantren Salaf Al-Anwar Sarang, Rembang, Jawa Tengah. Jenis penelitian deskriptif-kualitatif digunakan untuk menelaah dan memberikan interpretasi sesuai konteks perkembangan moderasi beragama di pesantren. ${ }^{14}$ Sasaran penelitian ini adalah kiai

7 Rustam Ibrahim, "Eksistensi Pesantren Salaf di Tengah Arus Pendidikan Modern”, Analisa: Journal of Social Science and Religion, Vol. 21, No. 2 (2014), 253.

8 Zamimah, "Moderatisme Islam", 89.

9 Sumarto dan Emmi Kholilah Harahap, "Mengembangkan Moderasi Pendidikan Islam Melalui Peran Pengelolaan Pondok Pesantren", Ri'ayah: Jurnal Sosial dan Keagamaan, Vol. 4, No. 01 (2019), 21-30.

10 Dwi Kusmira, "Moderatism of Pesantren Education in Indonesia", Jurnal Ilmiah Pesantren, Vol. 4, No. 2 (2018), 527.

${ }^{11}$ M. Kholid Thohiri, "Tradisi Pesantren Salafiyah dan Modern dalam Konteks Deradikalisasi”, dalam Proceedings of Annual Conference for Muslim Scholars, No. 2 (2018), 629-642.

12 Ahmad Agis Mubarok dan Diaz Gandara Rustam, "Islam Nusantara: Moderasi Islam di Indonesia", Journal of Islamic Studies and Humanities, Vol. 3, No. 2 (2019), 153-168.

13 Ismail, "Pesantren, Islam Moderat, dan Etika Politik dalam Perspektif Pendidikan Islam", dalam Proceedings of Annual Conference for Muslim Scholars, No. 2 (2018), 585-594.

${ }_{14}$ Deddy Mulyana dan Solatun, Metode Penelitian Komunikasi (Bandung: Remaja Rosdakarya, 2008), 5. 
dan santri di lingkungan pesantren yang memiliki informasi tentang perkembangan, model, dan implementasi kurikulum pesantre. Data dikumpulkan dengan teknik wawancara dan pengamatan. Analisis data dilakukan dengan pengelempokan dan memilah data sesuai dengan jenis dan kategorinya (reduksi data), kemudian di-display sesuai dengan kategori yang dipilih (display data), untuk kemudian diambil kesimpulan dan dilakukan verifikasi kembali untuk menemukan temuan yang valid. ${ }^{15}$

\section{Sejarah Perkembangan Pondok Pesantren Salaf Al-Anwar}

K.H. Maimoen Zubair mendirikan Pondok Pesantren Salaf AlAnwar (selanjutnya disebut Al-Anwar saja) pada tahun 1967. Cikal bakal pesantren ini dimulai dari bangunan musala kecil di depan rumahnya yang digunakan untuk pembelajaran bagi santri dan masyarakat yang datang untuk mendalami ilmu agama. Seiring dengan perkembangan jumlah santri yang terus bertambah, akhirnya musala tersebut dijadikan sebagai tempat tidur bagi santri yang inggin tinggal (mondok). Rutinitas kegiatan ngaji kitab inilah yang kemudian menjadi awal berdirinya Pondok Haji Maimoen (POHAMA). Setelah berjalan, pada akhirnya pondok tersebut diganti namanya menjadi Pondok Al-Anwar sebagai bentuk penghormatan kepada ayahnya yang bernama K.H. Anwar.

Al-Anwar berkembang sangat pesat. Saat ini ia memiliki empat pusat kegiatan berbasis pesantren. Pertama, Al-Anwar I yang menfokuskan pada pendalaman ilmu agama berbasis kitab-kitab klasik. Sejak awal berdirinya (1967) sampai tahun 2017, Al-Anwar I telah memiliki sembilan kompleks atau khos sebagai tempat mondok para santri, yang berlokasi di Desa Karangmangu, Sarang, Rembang. Kedua, Al-Anwar II yang memadukan antara ilmu agama dengan sains dan teknologi, yang berlokasi di Dusun Gondanrojo, Desa Kalipang, Sarang, Rembang. Ketiga, Al-Anwar III yang fokus pada pengembangan agama dalam jenjang pendidikan sarjana yang dikelola dalam Sekolah Tinggi Agama Islam (STAI) Al-Anwar. Keempat, Al-Anwar IV yang memadukan antara agama dengan teknologi melalui pengembangan pendidikan, Pendidikan tingkat

\footnotetext{
15 M.B. Miles and A.M. Huberman, Analisis Data Kualitatif, terj. Tjetjep Rohendi Rohidi (Jakarta: UI-Press, 1992), 92.
} 
SLTA dalam Lembaga Sekolah Menengah Kejuruan (SMK) AlAnwar di Desa Kalipang, Sarang. ${ }^{16}$

Berdasarkan informasi di atas, tampak bahwa Al-Anwar fokus pada dua pengembangan keilmuan, yaitu keilmuan agama dan pengetahuan umum. Keilmuan agama fokus mengkaji agama berbasis kitab-kitab klasik, sedangkang pengetahuan umum dikembangan melalui pendidikan formal MI, MTs, MA, SMK, dan STAI AlAnwar. Pengembangan pendidikan umum tidak terlepas dari keilmuan agama yang menjadi ciri khas Al-Anwar sebagai sebuah pesantren salaf.

\section{Pengembangan Kurikulum Sebagai Model Moderasi Beragama di Pondok Pesantren Al-Anwar}

Paham ekstrem lahir dalam segala dimensi kehidupan manusia, tidak terkecuali dalam memahami ajaran Islam. Perbedaan pemahaman dapat terjadi disebabkan cara pandang seseorang dalam menghadapi setiap problematika kehidupan. Perbedaan sudut pandang dalam memahami teks-teks ajaran Islam dapat disebabkan oleh persepsi yang berbeda dalam memahami suatu obyek kajian. Persepsi seseorang dalam memaknai suatu obyek dilatarbelakangi oleh latar belakang sosial, budaya, pendidikan, dan kerangka pengalaman seseorang.

Perilaku seseorang banyak ditentukan oleh cara pandang seseorang dalam memahami teks dan konteks peristiwa yang terjadi. Seseorang yang memiliki paham eksrem seringkali simetris dengan tindakan yang dilakukan dalam kehidupan sehari-hari. Paham ekstrem dalam konteks pemahaman ajaran agama melahirkan perilaku ekstrem dalam konteks agama. Ekstremitas keagamaan dalam istilah bahasa Arab disebut dengan tatarruf dini. Tatarruf atau ekstremitas memiliki arti berdiri di tepi dan jauh dari tengah. Seseorang yang memiliki pandangan ekstrem adalah orang yang memiliki pandangan yang berbeda jauh dengan pandangan umum yang sedang berkembang (pandangan di luar mainstream).

Tantangan umat Islam saat ini adalah keterbelakangan pendidikan, politik, dan ekonomi, di tengah berkembangnya pengetahuan dan teknologi, yang bersamaan dengan munculnya tuduhantuduhan terhadap umat Islam, seperti pendukung terorisme,

\footnotetext{
16 Pondok Pesantren Al-Anwar, "Dokumentasi Pondok Pesantren Al-Anwar", 17 Maret 2019.
} 
memusuhi wanita, dan anti kemajuan, ${ }^{17}$ dan adanya kelompokkelompok yang memiliki paham keagamaan yang berbeda dengan paham keagamaan umat Islam mayoritas. ${ }^{18}$

Islam adalah agama rạ̣matan li al-álamin. Pemahaman yang kurang tentang ajaran Islam menyebabkan terjadinya kesalahpahaman dalam memaknai Islam, bahkan menimbulkan paham anti-Islam. Dalam lintasan sejarah Islam, ada beberapa kelompok yang telah menampakkan sikap ekstremnya, misalnya; kelompok Khawärij yang pada masanya mereka mengkafirkan umat Islam lainnya yang memiliki pandangan dan pendapat yang berbeda dengan mereka. ${ }^{19}$ Ada juga kelompok Murji ${ }^{\prime a h}$ yang mememiliki pemahaman lebih longgar tentang ajaran dan tidak kaku. Paham Khawärij yang kaku identik dengan paham kelompok radikal, sedangkan kelompok Murï'ah lebih condong pada sikap kelompok liberal. ${ }^{20}$

Seiring dengan perkembangan pengetahuan dan teknologi yang tidak terbendung dalam kehidupan beragama dan bermasyarakat, paham radikal dan liberal juga tumbuh dan berkembang dengan cepat dalam ruang kehidupan beragama. Paham radikal yang kaku dalam implementasi kehidupan beragama, dan arus pemikiran ekstrem kelompok liberal saat ini, banyak melahirkan doktrin yang secara terus menerus menggerogoti akidah dan keyakinan umat Islam, misalnya; paham takfiri dari kelompok radikal, dan paham pluralisme dalam beragama dari kelompok liberal.

Paham liberalisasi agama berkembang sangat pesat, bahkan melebihi perkembangan paham radikal itu sendiri. Untuk mengantisipasi membanjirnya kedua paham tersebut dalam kehidupan umat Islam, diperlukan langkah-langkah yang cerdas agar umat Islam tidak berbelok arah dalam memahami ajaran Islam. Langkah-langkah yang harus dilakukan adalah penanaman dan penguatan nilai ajaran Islam sebagai dasar filosofi kehidupan

\footnotetext{
17 Muklis M. Hanafi, "Peran Al-Azhar dalam Penguatan Moderasi Islam", makalah dipresentasikan dalam Seminar Ikatan Alumni Al-Azhar Internasional (IAAI) Cabang Indonesia, Kerjasama Kedutaan Besar Mesir di Jakarta dengan Fakultas Dirasat Islamiyah UIN Syarif Hidayatullah, Jakarta (2013), 1.

18 Achmad Satori Ismail dkk., Islam Moderat: Menebar Islam Rabmatan lil 'Alamin (Jakarta: Pustaka Ikadi, 2007), 13-14.

19 Abū al-Fath Muhammad b. 'Abd al-Karīm al-Shahrastānī, al-Miläl wa al-Niḥäl (Syiria: Mu’assat al-Halabī, t.th.), 114.

20 Zamimah, "Moderatisme Islam", 77.
} 
dalam bermasyarakat dan membentuk tradisi keilmuan Islam yang kuat, menjauhkan pemikiran yang bersifat dikotomis, dan adanya penguatan dalam pendekatan wasatiyah. ${ }^{21}$ Tiga langkah ini memberikan alasan yang kuat bahwa pondok pesantren adalah salah satu media yang paling tepat sebagai rujukan umat Islam dalam mengembangkan sikap moderat dalam beragama. Ciri khas paham keagamaan yang dikembangkan di pondok pesantren adalah paham abl ls-sunnah wa al-jamá'ah yang moderat, menampilkan corak Islam yang santun, damai dan tidak memaksa, tidak juga ekstrem kanan maupun ekstrem kiri, serta mewarnai perkembangan dakwah Islam di Indonesia. ${ }^{22}$

Pesantren salaf sangat identik dengan organisasi keagamaan Nahdlatul Ulama (NU) yang menekankan pada moderasi Islam yang di bingkai dengan keserba-ibadahan, kemandirian, dan juga kesederhanaan yang bersumber dari penafsiran al-Qur'ān, hadīth, dan hasil interpretasi para ulama terdahulu. ${ }^{23}$ Pesantren terbukti mampu membawa nilai-nilai Islam dalam kehidupan bermasyarakat melalui transformasi pengetahuan keagamaan. ${ }^{24}$ Pesantren tidak hanya memiliki pendidikan khusus untuk mempelajari ilmu agama, tetapi juga menyelenggarakan pendidikan formal mulai tingkat yang paling bawah, yaitu Raudat al-Atfäl (Taman Kanak-kanak), sampai Perguruan Tinggi yang berada dan dikelola oleh pesantren. Hal ini sesuai dengan keterangan salah seorang informan sebagai berikut:

Al-Anwar pada awalnya dibagi menjadi dua, yaitu PP. Al-Anwar I yang dikhususkan bagi santri yang ingin mendalami ilmu-ilmu agama secara murni, dan PP. Al-Anwar II sebagai wadah bagi santri-santri yang ingin mempelajari sains dan teknologi tanpa meninggalkan pesantren sebagai wahana untuk mendalami ilmu agama. ${ }^{25}$

\footnotetext{
${ }^{21}$ Khalif Muammar, Atas Nama Kebenaran; Tanggapan Kritis terhadap Wacana Islam Liberal (Kuala Lumpur: Akademi Kajian Ketamadunan, 2006), 292.

${ }^{22}$ Mohamad Farid dan Ahmad Syafi'i, "Moderatisme Islam Pesantren dalam Menjawab Kehidupan Multikultural Bangsa”, Iqra': Jurnal Kajian Ilmu Pendidikan, Vol. 3, No. 1 (2018), 117-118.

23 Abd. A'la, NU dan Pesantren; Seirama dalam Politik (?) (Surabaya: Pustaka Idea, 2014), v.

24 Muhammad Muntahibun Nafis, Pesantren dan Pluralisme; Meretas Kerukunan Hidup Beragama Kaum Santri dengan "Al-Akhor" (Jakarta Timur: Maloho Jaya Abadi, 2009), 349.

${ }^{25}$ Informan B, Wawancara, 2019.
} 
Al-Anwar adalah sebuah pondok pesantren yang berhaluan akidah abl al-Sunnah wa al-jamäah, menggunakan sistem salafìyah dalam pembelajaran yang mengharuskan para santri untuk mengikuti pengajian mashäyikeh atau ustädh dengan pendekatan sistem bandongan dan sorogan. Model kurikulumnya berbasis pesantren salaf, yaitu pesantren yang masih mengajarkan kitab-kitab klasik, dan mengintegrasikan pengetahuan umum dalam dunia pesantren. ${ }^{26}$ Pemahaman agama santri diperluas melalui kegiatankegiatan Muhädarah atau Madrasah Ghazälìyah sampai tingkat aliyah. Selanjutnya para santri dapat menempa pendidikan agama melalui Ma'bad 'Ālì Iqna' al-Ṭälibin dengan jenjang pendidikan selama empat tahun.

Santri dalam kesehariannya diwajibkan mengikuti semua kegiatan pondok, baik kegiatan mengaji maupun sekolah. Semua kegiatan pesantren dilaksanakan dengan menggunakan acuan waktu istiw $\bar{a}$. Berikut informasi dari informan:

Semua santri memulai kegiatan dari pagi sekitar jam tujuh kurang seperempat untuk yang mubädarah, dan untuk yang MPG (Madrasah Putri Al Ghozaliyah) hampir setengah delapan, atau sekitar 07.15 harus sudah berangkat. Sementara untuk yang sekolah di Nggondan (Al-Anwar II) harus berangkat maksimal jam tujuh. Kemudian untuk muhạadarah selesai jam 12 kurang seperempat WIS (Waktu Istiwāa).27

Pesantren pada umumnya menetapkan waktu istiwa à dengan menggunakan tongkat, yang kemudian sering dikenal dengan 'tongkat istiw $\bar{a}$ ', untuk mengukur tinggi dalam bayangan matahari. Bayangan tongkat tersebut dapat digunakan untuk menentukan waktu salat Zuhur. ${ }^{28}$

Pesantren adalah prototype atau model pendidikan anti-paham radikal yang diintegrasikan dalam materi pembelajaran. ${ }^{29} \mathrm{Al}$-Anwar adalah model pesantren salaf yang mengintegrasikan materi pembelajaranya berbasis paham moderat, dan menjunjung tinggi

\footnotetext{
26 Rodli Sutrisno, "Pesantren Salaf di Tengah Pragmatisme Pendidikan", Tribakti: Jurnal Pemikiran Keislaman, Vol. 18, No. 2 (2007), 2.

${ }^{27}$ Informan C, Wawancara, 2019.

28 Anisah Budiwati, “Tongkat Istiwa', Global Positioning System (GPS) dan Google Earth untuk Menentukan Titik Koordinat Bumi dan Aplikasinya dalam Penentuan Arah Kiblat", Al-Abkam, Vol. 26, No. 1 (2016), 65-92.

${ }^{29}$ Novan Ardy Wiyani, "Pendidikan Agama Islam Berbasis Anti Terorisme di SMA", Jurnal Pendidikan Islam, Vol. 2, No. 1 (2013), 65.
} 
kemurnian kitab-kitab turäth dengan menggunakannya sebagai rujukan dalam kajian ilmu fiqh, seperti kitab Fath al-Qarib yang lebih sering disebut dengan Taqrï, tingkatan di atasnya ada kitab Fath al-Muin, dan secara terus menerus dikembangkan sesuai dengan kebutuhan. Pernyataan ini didukung oleh keterangan informan yang mengatakan: "kurikulumnya sebagaimana terjadwal, tanpa adanya pelajaran umum, dan hanya murni kitab salaf. Sedangkan pembelajarannya adalah sistem sekolah, musyawarah, dan hafalan, serta ada jam wajib belajar bersama di kelas sebelum musyawarah". 30 Informan lainnya mengatakan bahwa "kegiatan lain yang juga harus diikuti santri adalah Mudhäkarah yang meliputi mudhäkarah Fath al-Qarïb, Fatḥ al-Mu'in, dan Mahalli. Mudhäkarah merupakan suatu bentuk pembahasan secara mendalam pada kitab yang dikaji, juga penerapannya pada permasalahan-permasalahan yang ada". ${ }^{31}$

Santri pada tingkat awal belajar ilmu fiqh dengan menggunakan kitab kecil seperti Safinah dan Taqrib. Kitab-kitab kecil ini merupakan kitab fiqh yang berdasarkan pada mazhab Shāfíīi. Selanjutnya mempelajari kitab Käsyifat al-Sajä, Fatḥ al-Qarìb, Fath alMu'in dan sharb-nya, I'änah. Setelah itu semua, para santri kemudian dikenalkan dengan keragaman pendapat lain di luar pendapat madzhab Shāfíi $\overline{1}$ seiring dengan perubahan dan perkembangan zaman. $^{32}$

Pesantren merupakan "kawah candradimuka" bagi santri, sebelum mereka bergulat dalam kehidupan bermasyarakat; ${ }^{33}$ pesantren mengimplementasikan konsep wasatiyah dan al-ghuluw melalui kitab-kitab klasik. ${ }^{34}$ Karakter pesantren ini dimiliki oleh pesantren salaf yang berhaluan abl al-sunnah wa al-jamäah. Al-Anwar adalah sebuah pesantren salaf yang "kuat" dalam mendalami ilmu agama

\footnotetext{
${ }^{30}$ Informan B, Wawancara, 2019.

${ }^{31}$ Informan A, Wawancara, 2019.

32 Nadirsyah Hosen, "Mengenal Kitab Fiqih Perbandingan Madzhab", NU Online, 4 April 2017, https://islam.nu.or.id/post/read/76678/mengenal-kitabkitab-fiqih-perbandingan-mazhab.

33 Ahmad Muhakamurrohman, "Pesantren, Santri, Kiai, dan Tradisi", IBDA': Jurnal Kajian Islam dan Budaya, Vol. 12, No. 2 (2014), 110.

34 Mukhammad Abdullah, "Mengurai Model Pendidikan Pesantren Berbasis Moderasi Agama: Dari Klasik ke Modern”, Prosiding Nasional, Vol. 2 (2019), 5574.
} 
berdasarkan kitab-kitab klasik, yang diasuh seorang kiai yang sangat moderat. ${ }^{35}$

Secara geografis, letak pesantren ini berada di desa Karangmangu, Kecamatan Sarang, Kabupaten Rembang, Jawa Tengah. Pondok pesantren berbasis salaf ini, sebelumnya diasuh oleh seorang ulama terkenal yang pada bulan Agustus tahun 2019 meninggal di kota suci Mekah saat melaksanakan ibadah haji, dan dimakamkan di wilayah pemakaman khusus awliya $\bar{a}$ di sekitar Masjid al-Ḥarām, yaitu Shaykhinā Maimoen b. Zubair Dahlan yang di makamkan di Jannat al-Ma'lā. Ulama kharismatik yang seringkali dikenal dengan sebutan 'Mbah Moen' ini memiliki keahlian khusus dalam bidang sejarah peradaban Islam kuno. Di kalangan masyarakat luas, beliau dikenal sebagai seorang ahli sejarah. Pengasuh Pondok Pesantren Al-Anwar ini juga merupakan seorang kiai yang sangat moderat, ia menerima semua tamu yang datang meskipun berasal dari berbagai pemeluk agama selain Islam, kalangan miskin, dan juga pejabat, dengan tangan terbuka tanpa adanya penolakan. ${ }^{36}$

\section{Implementasi Moderasi Beragama di Pondok Pesantren Al- Anwar}

Pesantren adalah basis penanaman paham moderat untuk memenuhi karakteristik umat Islam yang telah di sebutkan dalam al-Qur'ān, yaitu ummatan wasatan (umat yang menjadi penengah di antara berbagai umat manusia); ${ }^{37}$ paradigma Islam wasatiyah mampu menjadi pembeda dalam mengatasi segala kemajemukan pendapat di tengah arus perbedaan sosio-kultural di Indonesia; ${ }^{38}$ sikap wasatīyah harus mampu diimpelementasikan dalam perilaku akidah, sharíah, dan tasawuf. ${ }^{39}$ Pesantren menjadi miniatur implementasi moderasi beragama yang tersirat atau implisit. Hal ini sesuai

\footnotetext{
35 Informan B, Wawancara, 2019.

${ }^{36}$ Ibid.

${ }^{37}$ Rizal Akhyar Musaffa, "Konsep Nilai-Nilai Moderasi dalam al-Qur'an dan Implementasinya dalam Pendidikan Agama Islam: Analisis al-Qur'an Surat alBaqarah 143" (Skripsi--UIN Walisongo Semarang, 2019), vii.

38 Edi Junaedi, "Inilah Moderasi Beragama Perspektif Kemenag", HARMONI, Vol. 18, No. 2 (2019), 184.

39 Achmad Yusuf, "Moderasi Islam dalam Dimensi Trilogi Islam (Akidah, Syariah, dan Tasawuf)", AL MURABBI: Jurnal Pendidikan Agama Islam, Vol. 3, No. 2 (2018), 203-216.
} 
dengan pernyataan informan sebagai berikut: "Kalau di Sarang tidak ada kajian khusus, akan tetapi setiap ngaji dengan kiai ataupun ustädh-nya, selalu diselipi dengan pembahasan tentang hal-hal ataupun peristiwa kekinian, termasuk tentang moderasi beragama". ${ }^{40}$

Pesantren sebagai lembaga pendidikan Islam yang menganut ajaran dan akidah abl al-sunnah wa al-jamā'ah memastikan bahwa semua santri yang berada di dalamnya telah dibekali ilmu-ilmu dasar mengenai konsep ajaran Islam moderat. Selain itu, santri dapat menauladani sikap dan perilaku keseharian kiai dan ustädh sebagai pengasuh pesantren yang dikenal sebagai tokoh yang moderat. Seorang informan memberikan keterangan sebagai berikut: "Sikap moderat lebih dicontohkan oleh para kiai dan ustädh secara langsung dalam kesehariannya, termasuk dalam cara cersikap, seperti itulah bagaimana kami para santri dididik, santri tidaklah radikal, ataupun teroris". ${ }^{41}$

Impelemtasi moderasi beragama sang kiai tercermin dalam ajaran yang diamalkan oleh para santri-santrinya. Doktrin ajaran sang kiai terdiri dari dua elemen dasar dalam amalan santri, yaitu: Pertama, seorang santri harus mempunyai ilmu khusus dan umum untuk orang lain. K.H. Maimoen semasa hidup merupakan sosok kiai yang 'alim, yang selama hidupnya senantiasa mengabdikan dirinya menjadi pelayan ilmu. Ia aktif mengajar para santri di pondok dan juga di Madrasah Ghazälìyah Shäfítyah (MGS), dan juga mengadakan pengajian rutin dalam Majlis Ta'lim yang mengkaji Tafsìr al-Jalālayn di musala Al-Anwar, yang sering disebut dengan "Ngaji Ahadan" yang diikuti santri, masyarakat umum, bahkan beberapa mashäizkh dari berbagai daerah. Cara K.H. Maimoen dalam penyampaian pesan dalam pengajian tafsir ayat-ayat alQur'ān begitu jelas dan gamblang, serta selalu mencoba mengaitkan sejarah-sejarah yang berhubungan dengan ayat-ayat tersebut. Selain itu, penerapan ayat-ayat tersebut juga dikaitkan antara zaman dahulu dengan zaman sekarang, sehingga semua penjelasan beliau mampu merasuk ke dalam hati para jamaah, dan sangat mudah dipahami dengan baik oleh berbagai kalangan. ${ }^{42}$ Ada perbedaan dalam cara penyampaian pesan dalam pengajian umum

\footnotetext{
40 Informan B, Wawancara, 2019.

${ }^{41}$ Ibid.

42 Amirul Ulum, Syaikhuna wa Usrotuhu (Rembang: LP. Muhadloroh PP. AlAnwar, 2016), 54.
} 
dengan khusus kepada para santri. Hal ini sesuai dengan keterangan dari informan sebagai berikut: "Jadi apa yang diajarkan pada santri di pondok, dengan apa yang di luar itu, berbeda dalam hal-hal semacam itu. Kalau di pondok itu lebih intern, jadi bisa ditunjukkan secara jelas mana yang semestinya salah. Kalau di luar begitu ya malah langsung rame". ${ }^{43}$

Sementara itu, seorang santri harus memiliki dan menguasai keilmuan khusus ketika berada di dalam atau dilingkungan pesantren dan juga keilmuan umum ketika terjun di lingkungan masyarakat luas. Hal ini sesuai dengan keterangan informan sebagai berikut: "Sebagaimana yang dilihat, meskipun tidak cocok dengan seseorang tetapi sebisa mungkin ketika di luar untuk tetap seakan-akan tidak ada apa-apa. Seperti Mbah Moen dengan Gus Dur itu tidak cocok akan pemikiran-pemikirannya tentang toleransi, tetapi beliau bisa tetap menguasai keadaan". ${ }^{44}$

Penguasaan keilmuan khusus amatlah penting agar seorang santri tetap dapat menjaga sikap moderat berdasarkan rumusan akidah abl al-sunnah wa al-jamäab (Aswaja) yang dipedomani. Islam pesantren yang disuarakan oleh para ulama Nusantara dan dimotori oleh para kiai secara sengaja memilih ajaran Islam Aswaja yang dalam konsepsinya memiliki perbedaan interpretasi dengan kelompok lain. Konsep Aswaja adalah pertautan pemikiran yang telah disarikan dari berbagai khazanah pemikiran dari para ulama abad pertengahan untuk diterapkan dalam kondisi dan situasi sosio-kultural bangsa Indonesia. Oleh karenanya, ia bukanlah Islam Aswaja ulama salaf yang murni dan bukan juga Aswaja yang diusung mentah-mentah dari belahan dunia Timur Tengah, akan tetapi merupakan Aswaja yang khas Indonesia. ${ }^{45} \mathrm{Hal}$ ini sesuai dengan keterangan informan sebagai berikut: "Menurut saya, ya Yai itu sangat moderat sekali, tidak ceroboh dalam toleransi dan tidak terlalu keras sebagaimana Habib Rizieq. Ia tidak cocok dengan model dakwah Habib Rizieq, tapi ia tidak lantas menghujat, melainkan ia tetap hormat". ${ }^{46}$

Habib Rizieq adalah salah satu pendiri Front Pembela Islam (FPI) yang diyakini merupakan salah satu keturunan Rasulullah.

\footnotetext{
43 Informan B, Wawancara, 2019.

${ }^{44}$ Ibid.

${ }^{45}$ Farid dan Ahmad Syafi'i, "Moderatisme Islam Pesantren", 117.

${ }^{46}$ Informan B, Wawancara, 2019.
} 
Meskipun pengikutnya kebanyakan berasal dari daerah lokal Jakarta, tetapi FPI mengklaim didukung oleh 15 juta simpatisan. ${ }^{47}$ Organisasi ini, tidak hanya mengedepankan aksi-aksi yang kontroversial, tetapi juga mengedepankan pemahaman dan interpretasi terhadap doktrin-doktrin Islam secara literal atau tekstual dengan alasan demi terjaganya kemurnian doktrin Islam secara utuh $(k \bar{a} f f a h) .{ }^{48}$

Model dakwah FPI tersebut secara keseluruhan sangat berbeda dengan model dakwah yang dilakukan oleh K.H. Maimoen di pesantren maupun di tengah masyarakat luas. Kredibilitas sang kiai sebagai da'i yang memiliki daya kharismatik dalam berdakwah tidak diragukan lagi. Ia berdakwah dengan menggunakan metode hikmah, maw'izah al-ḥasanah, dan mujädalah.

Kedua, mempertahankan eksistensi empat pilar dalam membentuk konsep nasionalis-religius kepada para santri. Dalam perkembangannya, negara Indonesia harus memiliki kreativitas dalam berpikir dan bernarasi sehingga tidak mudah terjebak dalam sekat-sekat pemahaman agama secara parsial dalam ruang sosial masyarakat. Pada titik ini, moderasi dalam beragama sebagai inti dari sebuah integrasi ajaran agama dapat disinergikan dengan berbagai keanekaragaman sosial-budaya yang dimiliki oleh bangsa Indonesia. Menteri Agama Lukman Hakim Saifuddin mengatakan agar moderasi beragama menjadi arus utama dalam corak keberagamaan masyarakat Indonesia. Beragama secara moderat sudah menjadi karakteristik umat beragama di Indonesia, dan lebih cocok diterapkan untuk kultur masyarakat Indonesia yang majemuk.

Beragama secara moderat sudah menjadi karakteristik umat beragama di Indonesia, dan pada dasarnya memang lebih cocok diterapkan untuk kultur masyarakat Indonesia yang majemuk. Beragama secara moderat adalah model beragama yang telah lama dipraktikkan dan tetap diperlukan pada era sekarang. ${ }^{49}$ K.H.

\footnotetext{
${ }^{47}$ Siti Masyitoh, "Metode Dakwah Habib Rizieq Bin Husein Syihab pada Majlis Ta’lim Jami Al-Ishlah Jakarta Pusat" (Skripsi--UIN Syarif Hidayatullah Jakarta, 2012), 7.

48 Agus Ali Dzawafi, "Pemahaman Tekstual Dan Implikasinya terhadap Gerakan Dakwah Front Pembela Islam (FPI)", Adrikra: Jurnal Komunikasi dan Penyiaran Islam, Vol. 3, No. 1 (2012), 34.

49 Edy Sutrisno, "Aktualisasi Moderasi Beragama di Lembaga Pendidikan", Jurnal Bimas Islam, Vol. 12, No. 2 (2019), 326.
} 
Maimoen sebagai seorang ulama dan juga guru bangsa memiliki tanggung jawab untuk mengimplementasikan model moderasi beragama dalam kehidupan pesantren dan masyarakat umum. Implementasi moderasi beragama dapat berupa sikap saling menghormati dan toleransi pada pihak lain, serta tidak memaksakan kehendak pada orang lain, bahkan tidak diperbolehkan bersikap secara fanatik buta. ${ }^{50}$ K.H. Maimoen selalu mengajarkan kepada para santrinya untuk tidak menjadi orang yang fanatik. Pernyataan ini diperkuat oleh keterangan informan sebagai berikut:

Mbah Yai itu setiap ngaji selalu menyampaikan pesan (ngendikan), kalau jadi orang itu jangan jadi orang yang fanatik, karena Islam itu tidak fanatik. Kepada para santrinya, Mbah Yai selalu menyampaikan pesan (ngendikan) untuk jadi santri yang nasionalis dan juga religius, sebagaimana yang diajarkan oleh Nabi Muhammad". ${ }^{51}$

K.H. Maimoen dalam setiap pengajiannya selalu menanamkan konsep nasionalis-religius sebagai sebuah konsep kebangsaan. Menurut K.H. Maimoen, santri sebagai warga negara Indonesia yang memiliki potensi untuk meneruskan perjuangan para ulama harus memiliki sikap nasionalis dan tingkat religiusitas yang tinggi. Dalam konsep nasionalis-religius tersebut, K.H. Maimoen juga merinci adanya empat pilar yang harus dipertahankan oleh para santri dan masyarakat untuk Indonesia. Pesan khusus untuk santri dan masyarakat ini dapat dilihat dalam dokumentasi Al-Anwar sebagai berikut:

Sekarang di abad keempat belas, benar apa yang difirmankan oleh Allah:

$$
\text { المُ تر أَن الله أنزل من السماء ماء }
$$

Adakah engkau tidak mengetahui bahwa Allah menurunkan air dari langit.

Apa air itu? kehidupan. Apa kehidupan itu? persatuan. Apa persatuan itu? mengokohkan. Manusia itu saling mengokohkan dan tidak bisa dipisahkan dengan sesama manusia yang lain. Ini umpamakan seperti air. Kemudian selanjutnya Allah berfirman:

$$
\text { فاخرجنا به من الثمرات خختلف الواخا }
$$

Dari air itu, timbul kelompok-kelompok yang berbeda.

Beda tapi sama, sama tapi beda.

\footnotetext{
50 Agus Akhmadi, "Moderasi Beragama dalam Keragaman Indonesia", INOV ASI: Jurnal Diklat Keagamaan, Vol. 13, No. 2 (2019), 45.

${ }^{51}$ Informan C, Wawancara, 2019.
} 
Allah meneruskan dalam firman tersebut:

$$
\text { ومن جبال جدد بيض وحمر ختلف الوانه }
$$

Dari kekuatan-kekuatan, ada gunung-gunung yang berdiri kokoh. Itu adalah jalan terang menuju arah persatuan bangsa. Dalam firman Allah itu disebutkan makna putih dan merah. Jadi, jika di zaman nabi dulu dikatakan putih dan merah itu, sekarang kita bangsa Indonesia dikatakan merah dan putih. Kalau tidak ada merah, tidak ada semangat, tidak ada darah. Kalau tidak ada putih, tidak ada keikhlasan, tidak ada kekuatan. Makanya bendera bangsa Indonesia berwarna merah-putih. Kalau dulu putih merah, sekarang merah-putih.

Saya ingatkan di sini, bahwa bangsa Indonesia diproklamirkan pada tanggal 17 Agustus, bertepatan tanggal 8 Ramadhan. Sama dengan Kanjeng Nabi diangkat resmi menjadi pembawa risalah Tuhan pada tanggal 8 Agustus, bertepatan tanggal 17 Ramadhan. Apa yang terjadi? Nabi dikatakan pernah hijrah dari kota Mekah menuju kota Madinah pada bulan Oktober. Sedangkan pemerintahan Republik Indonesia pernah hijrah dari ibu kota negara, Jakarta ke Jogjakarta, Jawa Tengah, saat Agresi Militer Belanda datang. Oleh karena itu, RI waktu dulu diserang, kira-kira usia saya sudah berumur 20 tahun lebih, tahu bahwa pusatnya negara Indonesia berada di Jawa Tengah.

Mudah-mudahan acara yang bertepatan dengan bulan Rajab ini mendapat keberkahan. Saya masih ingat, dulu waktu ramairamainya apa yang disebut pernyataan kemerdekaan bangsa Indonesia di mulai bulan Rajab, kemudian bulan Sya'ban dan memasuki bulan Ramadhan, bangsa Indonesia memproklamirkan diri sebagai negara merdeka. Oleh karena itu, kepada kawankawan saya, saudara-saudara saya di Jawa Tengah, Jawa Tengah ini merupakan Central Java.

Sejarah bangsa Indonesia tidak luput dari berdirinya NU pada tahun 1926 M. Namun Muktamar NU yang pertama kali didatangi oleh para cabang-cabang di seluruh Indonesia terjadi pada tahun 1928 M. Tahun bersejarah ini sama dengan peristiwa terjadinya Sumpah Pemuda. Dalam Sumpah Pemuda itu, para pemuda berikrar Satu Nusa, Satu Bangsa, dan Satu Bahasa. Dan akhirnya ditambah Satu Nusa, Satu Bangsa, Satu Bahasa, Satu Tanah Air. Inilah empat pilar penting bangsa Indonesia.

Nabi saat membentuk sebuah negara di Madinah tidak keluar dari negeri Arab. Kanjeng Nabi tetap berjiwa nasionalis dan membawa misi bithah ilähiyah.

Inilah yang perlu saya utarakan. Saya serukan Jawa Tengah supaya benar-benar al-awal wal akhir, pertama sampai tak ada 
habisnya-habisnya. Jadikanlah Jawa Tengah seperti NU saat mengadakan Muktamar yang dihadiri cabang-cabangnya di seluruh Indonesia. Jadikanlah Jawa Tengah sebagai jujukan pemerintahan Republik Indonesia sebagaimana pada bulan Oktober dulu pusat pemerintahan Indonesia dipindah (hijrah) ke Jogjakarta, Jawa Tengah. Sama dengan Nabi. Nabi proklamasi Agustus tapi Hijrah ke Madinah bulan Oktober. Persamaan ini, merah-putih. Dulu di al-Qur'an dikatakan putih-merah, sekarang merah-putih. Podo tapi bedo, bedo tapi podo.

Sekian saya mohon maaf. Mudah-mudahan apa yang kita maksud kumpul di Simpang Lima ini semuanya kembali kepada Pancasila. Ketahuilah bahwasannya Pancasila mempunyai segi empat. Empat segi itu mengepung Ketuhanan yang Maha Esa. Sehingga Indonesia jika masih berpegang pada empat pilar ini akan tetap ada dan merdeka. Yaitu Pancasila, Bhinneka Tunggal Ika, Negara Kesatuan Republik Indonesia, Undang-Undang 45 yang disebut PBNU. Sekian. ${ }^{52}$

K.H. Maimoen adalah seorang ulama sekaligus ahli sejarah, yang selalu menceritakan dan menjelaskan dalam setiap tausiahnya tentang bagaimana proses sejarah negara Indonesia dan seberapa besar peran umat Islam di dalamnya. K.H. Maimoen selalu mengajarkan kepada para santri untuk selalu menjunjung tinggi sikap nasioanlisme. Shāfi ${ }^{\leftarrow} \overline{1}$ pernah mengemukakan pemikirannya tentang pemuda-pemuda di masa depan, tidak terkecuali kaum santri, bahwa "sungguh pemuda itu diukur dari kualitas ilmu dan ketakwaannya, jika keduanya tidak melekat pada struktur kepribadiannya, maka ia tidak layak untuk disebut pemuda”. Kaum santri yang notabene hidup di lingkungan pesantren dan mendapat pendidikan di bawah asuhan para kiai, merupakan panji-panji pembawa kemajuan agama dan negara. Seperti ungkapan dari sebuah maqälah bahwa "shubbān al-yawm rijäl al-ghad" (pemuda saat ini adalah pemimpin dimasa depan)..$^{53}$

Shaykh Rajab Dīb al-Subkī dalam kunjungannya ke Al-Anwar mengatakan bahwa pemuda yang baik adalah pemuda yang berperilaku sesuai dengan perilaku orang-orang pesantren. Berdasarkan memori sejarah yang ada, ulama merupakan

\footnotetext{
52 Pondok Pesantren Al-Anwar, "Dokumentasi Pesan K.H. Maimoen Zubair", 17 Maret 2019.

53 Sabolah Al Kalamby, "Generasi Muda dan Jalan Terjal Pemilu 2019," NU Online, 12 April 2019, https://www.nu.or.id/post/read/104753/generasi-mudadan-jalan-terjal-pemilu-2019.
} 
pemegang tongkat estafet dari para Nabi. Oleh karenanya, sebaikbaiknya tempat atau majlis adalah majlisnya para ulama, dan pondok pesantren merupakan majlis ulama. Dalam pondok pesantren terdapat banyak ilmu yang siap ditransformasikan kepada masyarakat. Pesantren membuka peluang yang besar bagi para pemuda-pemudi untuk untuk ngalap ilmu dari para ulama yang mengasuh pondok pesantren. ${ }^{54}$

Implementasi moderasi beragama di pesantren minimal dapat dilakukan oleh orang yang beraktivitas dan tinggal di pesantren. Orang-orang tersebut terdiri dari kiai, keluarga kiai, asätìdh, khaddam, dan santri. ${ }^{55}$ Kiai adalah pengasuh pesantren yang memiliki peran sebagai tokoh sentral dalam mengelola pesantren; keluarga kiai adalah istri, anak, dan saudara-saudara yang lain yang tinggal di pesantren; asätìdh adalah para guru yang membantu kiai dalam membina para santri; khaddām adalah orang yang membantu menyelesaikan urusan-urusan kiai dan keluarganya; dan santri adalah murid yang belajar dan tinggal di pesantren. Lima komponen orang pesantren ini dapat menyebarkan paham moderasinya dalam pelbagai bentuk kepada masyarakat.

\section{Penutup}

Al-Anwar merupakan sebuah lembaga pendidikan Islam yang sangat masyhur dengan penerapan sistem pendidikan salafíyab; salah satu pondok pesantren yang sangat dipercaya masyarakat karena kualitas keilmuannya yang tumbuh dan berkembang dengan sangat pesat. Al-Anwar menggunakan kurikulum salaf sebagai model moderasi beragama yang ditanamkan kepada para santri dan masyarakat melalui semua materi pembelajaran pondok pesantren yang dipusatkan pada bahan berupa kitab-kitab turäth. Kredibilitas yang dimiliki K.H. Maimoen, sang pengasuh, menjadikannya sosok ulama yang disegani yang menjadi rujukan seluruh umat Islam khususnya umat Nahdliyin. NU menjadi rujukan K.H. Maimoen dalam berdakwah, dengan paham Aswaja-nya, yang sangat mengedepankan sikap moderasi dalam beragama. Implementasi moderasi beragama di Al-Anwar dilakukan melalui perilaku dan

54 Amirul Ulum, "Mencetak Kader-Kader Islami”, 9 April 2013, http://ppalanwar.com/index.php/news/509/34/Mencetak-Kader-KaderIslami.html.

55 Ali Nurdin, "Tradisi Komunikasi di Pesantren", KARS A: Journal of Social and Islamic Culture, Vol. 23, No. 2 (2015), 279-280. 
sikap moderat santri dalam meghadapi berbagai problematika pemikiran akidah, muamalah, dan dimensi kehidupan sosial yang lain. Sikap moderat lahir sebagai akibat dari tempaan pendidikan di pesantren yang menanamkan karakter dan kepribadian para santri yang memiliki kesadaran diri, dan harus memiliki keilmuan khusus untuk dirinya sendiri dan keilmuan umum untuk masyarakatnya. Selain itu, sebagai generasi penerus bangsa, santri harus memegang kuat empat pilar yang dirumuskan oleh K.H. Maimoen, yang disingkat menjadi PBNU, yaitu; Pancasila, Bhinneka Tunggal Ika, Negara Kesatuan Republik Indonesia (NKRI), dan UndangUndang Dasar 1945.

\section{Daftar Rujukan}

A'la, Abd. NU dan Pesantren; Seirama Dalam Politik. (?). Surabaya: Pustaka Idea, 2014.

Abdullah, Mukhammad. "Mengurai Model Pendidikan Pesantren Berbasis Moderasi Agama: Dari Klasik ke Modern", Prosiding Nasional, Vol. 2, 2019.

Akhmadi, Agus. "Moderasi Beragama dalam Keragaman Indonesia", INOV ASI: Jurnal Diklat Keagamaan, Vol. 13, No. 2, 2019.

Al Kalamby, Sabolah. "Generasi Muda dan Jalan Terjal Pemilu 2019," NU Online, 12 April 2019, https://www.nu.or.id/post/read/104753/generasi-muda-danjalan-terjal-pemilu-2019.

Anwar, Ali. Pembaruan Pendidikan di Pesantren Lirboyo Kediri (Kediri: IAIT Press, 2008), 1.

Budiwati, Anisah. "Tongkat Istiwa', Global Positioning System (GPS) dan Google Earth untuk Menentukan Titik Koordinat Bumi dan Aplikasinya dalam Penentuan Arah Kiblat", AlAbkam, Vol. 26, No. 1, 2016.

Dzawafi, Agus Ali. "Pemahaman Tekstual Dan Implikasinya terhadap Gerakan Dakwah Front Pembela Islam (FPI)", Adrikra: Jumal Komunikasi dan Penyiaran Islam, Vol. 3, No. 1, 2012.

Farid, Mohamad, dan Ahmad Syafi'i. "Moderatisme Islam Pesantren dalam Menjawab Kehidupan Multikultural Bangsa", IQR A': Jurnal Kajian Ilmu Pendidikan, Vol. 3, No. 1, 2018.

Hanafi, Muklis M. "Peran Al-Azhar dalam Penguatan Moderasi Islam", Seminar Ikatan Alumni Al-Azhar Internasional (IAAI) 
Cabang Indonesia, Kerjasama Kedutaan Besar Mesir di Jakarta dengan Fakultas Dirasat Islamiyah UIN Syarif Hidayatullah, Jakarta, 2013.

Hosen, Nadirsyah. "Mengenal Kitab Fiqih Perbandingan Madzhab", NU Online, 4 April 2017, https://islam.nu.or.id/post/read/76678/mengenal-kitabkitab-fiqih-perbandingan-mazhab.

Ibrahim, Rustam. "Eksistensi Pesantren Salaf di Tengah Arus Pendidikan Modern", Analisa: Journal of Social Science and Religion, Vol. 21, No. 2, 2014.

Ismail, Achmad Satori, dkk. Islam Moderat: Menebar Islam Rabmatan lil'Alamin. Jakarta: Pustaka Ikadi, 2007.

Ismail. "Pesantren, Islam Moderat, dan Etika Politik dalam Perspektif Pendidikan Islam", Proceedings of Annual Conference for Muslim Scholars, No. 2, 2018.

Junaedi, Edi. "Inilah Moderasi Beragama Perspektif Kemenag", HARMONI, Vol. 18, No. 2, 2019.

Kusmira, Dwi. "Moderatism of Pesantren Education in Indonesia", Jurnal Ilmiah Pesantren, Vol. 4, No. 2, 2018.

Madjid,Nurcholis. Islam Kemodernan dan Keindonesiaan. Bandung: MIZAN, 1993.

Masyitoh, Siti. "Metode Dakwah Habib Rizieq Bin Husein Syihab pada Majlis Ta'lim Jami Al-Ishlah Jakarta Pusat". Skripsi--UIN Syarif Hidayatullah Jakarta, 2012.

Miles, M.B., and A.M. Huberman. Analisis Data Kualitatif, terj. Tjetjep Rohendi Rohidi. Jakarta: UI-Press, 1992.

Muammar, Khalif. Atas Nama Kebenaran; Tanggapan Kritis terhadap Wacana Islam Liberal. Kuala Lumpur: Akademi Kajian Ketamadunan, 2006.

Mubarok, Ahmad Agis, dan Diaz Gandara Rustam. "Islam Nusantara: Moderasi Islam di Indonesia", Journal of Islamic Studies and Humanities, Vol. 3, No. 2, 2019.

Muhakamurrohman, Ahmad. "Pesantren, Santri, Kiai, dan Tradisi", IBD A': Jumal Kajian Islam dan Budaya, Vol. 12, No. 2, 2014.

Mulyana, Deddy, dan Solatun. Metode Penelitian Komunikasi. Bandung: Remaja Rosdakarya, 2008.

Musaffa, Rizal Akhyar. "Konsep Nilai-Nilai Moderasi dalam alQur'an dan Implementasinya dalam Pendidikan Agama Islam: 
Analisis al-Qur'an Surat al-Baqarah 143". Skripsi--UIN Walisongo Semarang, 2019.

Nafis, Muhammad Muntahibun. Pesantren dan Pluralisme; Meretas Kerukunan Hidup Beragama Kaum Santri dengan "Al-Akhor". Jakarta Timur: Maloho Jaya Abadi, 2009.

Nurdin, Ali. "Tradisi Komunikasi di Pesantren", KARSA: Journal of Social and Islamic Culture, Vol. 23, No. 2, 2015.

Pondok Pesantren Al-Anwar. "Dokumentasi Pesan K.H. Maimoen Zubair”, 17 Maret 2019.

Pondok Pesantren Al-Anwar. "Dokumentasi Pondok Pesantren Al-Anwar", 17 Maret 2019.

Qardhawi, Yusuf. Islam Ekstrem: Analisis dan Pemecahannya. Bandung: MIZAN, 1993.

Shahrastān̄̄ (al), Abū al-Fatḥ Muhammad b. 'Abd al-Karīm. alMiläl wa al-Niḥäl. Syiria: Mu’assat al-Ḥalabī, t.th.

Sumarto, dan Emmi Kholilah Harahap. "Mengembangkan Moderasi Pendidikan Islam Melalui Peran Pengelolaan Pondok Pesantren", Ri'ayah: Jurnal Sosial dan Keagamaan, Vol. 4, No. 1, 2019.

Sutrisno, Edy. "Aktualisasi Moderasi Beragama di Lembaga Pendidikan”, Jurnal Bimas Islam, Vol. 12, No. 2, 2019.

Sutrisno, Rodli. "Pesantren Salaf di Tengah Pragmatisme Pendidikan", Tribakti: Jurnal Pemikiran Keislaman, Vol. 18, No. 2, 2007.

Taymiyah, Ibn. al-Amr bi al-Ma'rüf wa al-Naby 'an al-Munkar, ed. Ṣalāḥ al-Dīn al-Munajjad (Beirut: Dār al-Kitāb al-Jadīd, 1396), 40.

Thohiri, M. Kholid. "Tradisi Pesantren Salafiyah dan Modern dalam Konteks Deradikalisasi”, Proceedings of Annual Conference for Muslim Scholars, No. 2, 2018.

Ulum, Amirul. "Mencetak Kader-Kader Islami”, 9 April 2013, http://ppalanwar.com/index.php/news/509/34/MencetakKader-Kader-Islami.html.

Ulum, Amirul. Syaikhuna wa Usrotubu. Rembang: LP. Muhadloroh PP. Al-Anwar, 2016.

Wahid, Abdurrahman. Menggerakean Tradisi: Esai-Esai Pesantren. Yogyakarta: LKiS, 2001. 
Wiyani, Novan Ardy. "Pendidikan Agama Islam Berbasis Anti Terorisme di SMA", Jurnal Pendidikan Islam, Vol. 2, No. 1, 2013.

Yusuf, Achmad. "Moderasi Islam dalam Dimensi Trilogi Islam (Akidah, Syariah, dan Tasawuf)", AL MURABBI: Jurnal Pendidikan Agama Islam, Vol. 3, No. 2, 2018.

Zamimah, Iffati. "Moderatisme Islam dalam Konteks Keindonesiaan (Studi Penafsiran Islam Moderat M. Quraish Shihab)", Al-Fanar: Jurnal Ilmu Al-Qur'an dan Tafsir, Vol. 1, No. 1, 2018.

\section{Wawancara}

Informan A. Wawancara. 2019.

Informan B. Wawancara. 2019.

Informan C. Wawancara. 2019. 